\title{
Insectacaricides treatment timing against thrips in cotton as a protection to entomophage
}

\author{
Istam Saidov ${ }^{1, *}$, Ulfat Abdullaeva ${ }^{1}$, Mukhabbat Mirzaeva ${ }^{1}$, Gulbakhor Esemuratova ${ }^{1}$, \\ Dilyara Rizaeva ${ }^{1}$, and Rano Abdumajidova ${ }^{1}$ \\ ${ }^{1}$ Tashkent State Agrarian University, University str., 2, Tashkent province, Uzbekistan, 100140
}

\begin{abstract}
One of the objectives of our research was to study the acute and residual toxicity of some modern insecticides and acaricides on natural and laboratory populations of known entomophages. The experiments were carried out in the growing season of 2016 and 2017 in the laboratory of the Department of Entomology TSAU and the experimental base of the university. For experiments, widely used (Bi-58, Omite), as well as modern insecticides recommended for the PPIS - Vaulent, Mospilane were taken.
\end{abstract}

\section{Introduction}

Since independence, agriculture has undergone significant reforms $[1,2,11]$, including in plant protection. One of the directions is the identification of the composition of thrips and their entomophages in agrobiocenoses of cotton and vegetable crops. Globally, in countries with developed agriculture, greenhouse thrips (Heliothrips haemorrhoidalis Bouche) is spreading on vegetable crops grown in greenhouses and open field, causing significant damage [1]. Due to the harmfulness caused by this pest, there is a decrease in the yield of vegetable crops, deterioration in their quality $[2,12]$. In this regard, in many countries, including also in Uzbekistan, the study of greenhouse thrips and the development of effective measures to combat it remains an urgent problem. One of the ways to increase the yield of tomato and other vegetable crops is to protect plants from various diseases and pests [3]. Due to the absence of protective measures, the yield and its quality decreases [3, 13]. In the last decade, the expansion of trade in various agricultural products, as well as through interstate tourism, transport and partly natural migration, has exacerbated the problem of the penetration of various species of adventive (alien) harmful insects [2-4].

In the existing territory of Uzbekistan, as a result of the harmful influence of thrips, up to $30-40 \%$ of the yield of cultivated vegetable crops is lost $[1,5,11]$. In this regard, it is important to ensure food security in Uzbekistan, the cultivation of products based on scientifically based technologies and means that have their place in the world market $[5,14$, 15]. The Action Strategy for the further development of the Republic of Uzbekistan in 2017-2021 outlines the tasks in priority areas "... the development and implementation of measures to protect plants from diseases and pests." Accordingly, an important task is the development and implementation into production practice of an integrated pest control system for the cultivation of vegetable crops in greenhouses [16].

* Corresponding author: i.r.saidov@yandex.com 
Establishing the species diversity of dominant species, biological characteristics of their development and harmfulness of herbivorous thrips, and therefore their role in agrobiocenoses, is an urgent task of entomology in theoretical and practical terms [1-5]. One of the tasks of the further development of the Republic of Uzbekistan, noted in the Directions of the Strategy for the Development of Agriculture, is "... the introduction of intensive technologies in plant protection." The study of the world entomofauna is directly related to plant growing and the development of phytophages in agrobiocenoses, their harmful effect on the yield, volume and quality of agricultural crops. In this regard, when carrying out the necessary measures from year to year, problems are observed that affect the cost of the crop, which leads to a decrease in consumption and a decrease in agricultural production in the world $[15,16]$.

These acute environmental problems in the world require their solution, the creation of new technologies, and continuous improvement of their scientific and practical implementation in this area. These also include the creation of the possibility of using biological and chemical methods of control in the fight against thrips in cotton and vegetable crops, increasing the efficiency of their application and carrying out scientific and research work in this direction.

One of the objectives of our research was to study the acute and residual toxicity of some modern insecticides and acaricides on natural and laboratory populations of known entomophages.

\section{Materials and methods}

The material of the research was the study of acute and residual toxicity of some modern insecticides and acaricides on natural and laboratory populations of known entomophages. The experiments were carried out during the growing season of 2016 and 2017 in the laboratory of the Department of Entomology of the TSAU and the experimental base of the university. For the experiments, widely used (Bi-58, Omayt), as well as modern insecticides recommended for PPIS were taken (List of the State Chemical Commission, 2016) Vaulent, Mospilane [5-7].

The experiment used the technique recommended for these purposes [8-10]. First, limited areas with cotton (height $45-60 \mathrm{~cm}$ ) were treated, and then, after a certain time, the leaves were cut off from them and, in laboratory conditions (in Petri dishes), were offered for contact or feeding to experimental entomophages.

\section{Results and discussion}

The scheme of experiments and the results obtained are presented in Table 1, from which the following can be seen.

1. Insecticide Vaulent, with an active substance - indoxacarb, is a highly specific preparation for the control of caterpillars of various insects. It does not have a detrimental effect on individual phases of development of lacewings and predatory mites phytoseiulus. Therefore, this is a clear representative of those drugs that should be used in IPM.

2. Insecticide Mospilane from the neonicotinoid class is an effective drug against many types of sucking insects, including thrips. Along with this, Mospilan had a destructive effect on lacewing and is almost non-toxic to phytoseiulus. 
Table 1. Safe timing of cotton treatments with insectoacaricides against thrips, ensuring protection of entomophages.

Laboratory and field experiments, 2016-2017.

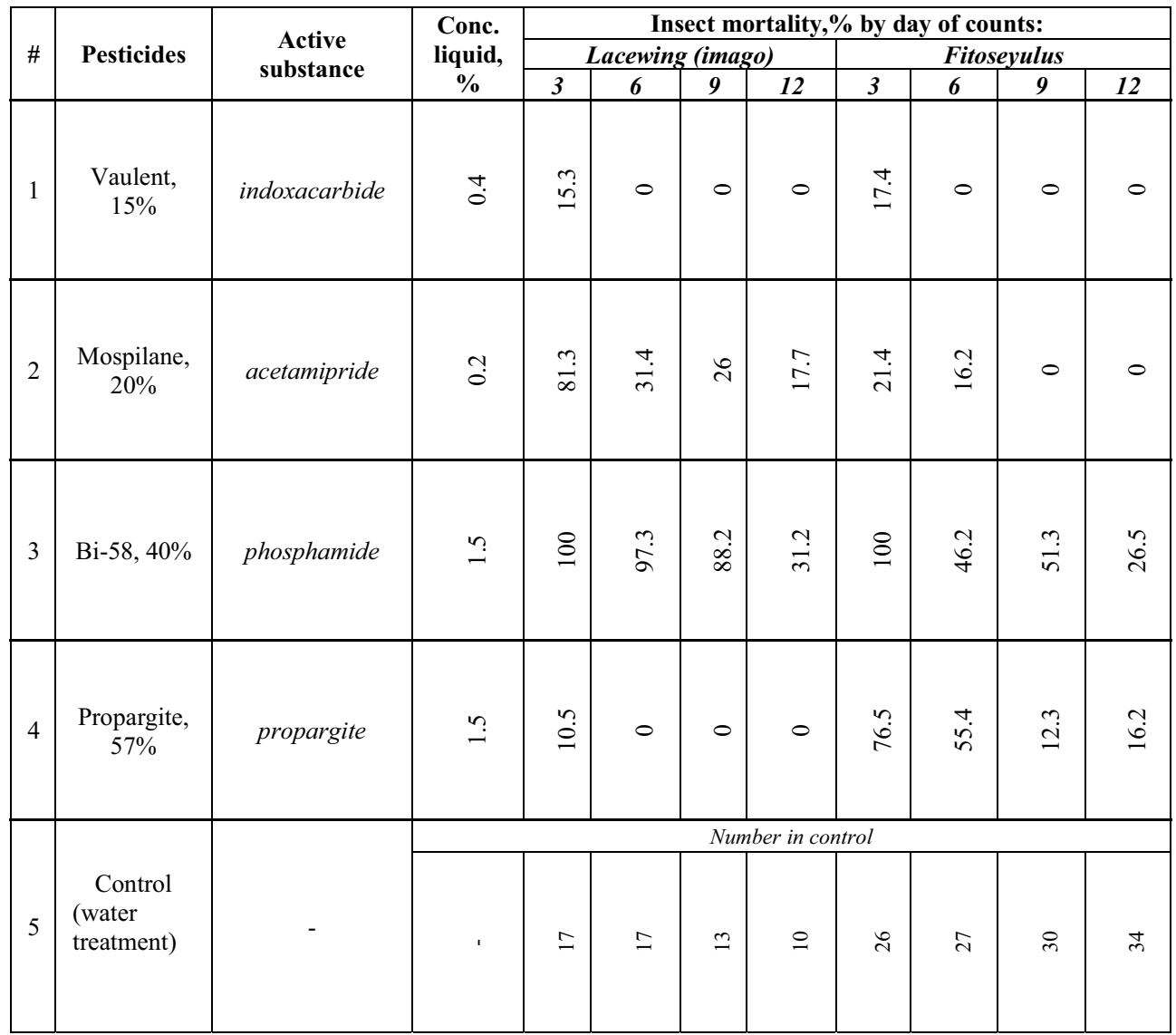

3. Organophosphate Bi-58 (phosphamide) is an insectoacaricide, therefore its high efficiency against a complex of sucking and gnawing pests is accompanied by its toxicity for entomophages of cotton agrobiocenosis, in particular lacewings and other entomophagous insects, as well as phytoseiulus.

4. The specific acaricide propargite has been used in Uzbekistan for a long time. Despite this, the spider mite did not play resistance to it - it continues to be sensitive, and the lacewing is not sensitive to it.

Insecticides, which have long been used in agriculture of the republic, as well as some of the modern (promising) ones, differ in toxicity for entomophages dominating in agrobiocenoses. Thus, insecticide $\mathrm{Bi}-58(0.15 \%)$ turned out to be highly toxic for all developmental phases of lacewings and acariphagus - ambliseyulus, and Omite $(0.15 \%)$ only against the tick - acariphage. Vaulent $(0.04 \%)$ is practically safe against all entomophages, despite the fact that it is one of the most effective and promising insecticides against cotton bollworm. Mospilan $(0.02 \%)$ is toxic only for insectsentomophages for 6 days.

It is shown that the most optimal temperature for the development of greenhouse thrips is $25-30{ }^{\circ} \mathrm{C}$, the relative humidity is $60-65 \%$, under such conditions the pest on cucumbers and tomatoes can give 5-7 generations in one season (March-June). In addition, it was 
revealed that in winter in greenhouses on various plants it gives another 3-4 generations, and in just 1 year 8-11 generations.

\section{Conclusions}

Insecticides, which have long been used in the agriculture of the republic, as well as some of the modern (promising) ones, differ in toxicity for entomophages dominating in agrobiocenoses. Thus, insecticide Bi-58 $(0.15 \%)$ turned out to be highly toxic for all developmental phases of lacewings and acariphagus - ambliseyulus, and Omite $(0.15 \%)$ only against the tick - acariphage. Vaulent $(0.04 \%)$ is practically safe against all entomophages, despite the fact that it is one of the most effective and promising insecticides against cotton bollworm. Mospilane $(0.02 \%)$ is toxic only for insectsentomophages for 6 days.

The new improved technology for protecting cotton from thrips provided an additional yield of raw cotton in the amount of 3-4 quintals/ha, and onion - 11-12 quintals/ha. The justification of 1 UZS of costs for crop protection using the improved technology was an additional 4.0-5.1 UZS.

\section{References}

1. H. H. Kimsanbaev, Lacewing, 1, 4-54 (1999)

2. H. Kimsanbaev, A. Sagdullaev, K. Khalilov, Methods of Combating Pests and Diseases of Grain, Cotton, Vegetables, and Horticultural Crops, 127 (2007) (in Uzbek)

3. H. Kimsanbaev, V. Avtonomov, J. Bobobekov, Phytosanitary Improvement of Ecosystems, 2, 238-244 (2015)

4. M. N. Kaznachaev, Journal of Plant Protection and Quarantine, 6, 10-11 (2015)

5. B. C. Akehurst, Tobacco, 763 (1991)

6. H. F. Van Emden, J. Sei. Fd. Agric., 20, 385-387 (2019)

7. R. F. Smith, World Health Organization Report, 48, 685-698 (1993)

8. D. L. Kerns, M. J. Gaybor, South West. Entomol., 17, 244-247 (2017)

9. S. M. Vidyasekhar, G. P. V. Reddy, Pesticides, 23(8), 45-48 (2009)

10. M. V. Vecaria, G. M. Patel, Indian Journal of Entomology, 62(2), 150-158 (2010)

11. R. A. Kulmatov, S. A. Adilov, S. Khasanov, In IOP Conference Series: Earth and Environmental Science, 614(1), 012149 (2020)

12. I. Aslanov, S. Khasanov, Y. Khudaybergenov, M. Groll, Ch. Opp, F. Li, E. Ramirez Del-Valle, In E3S Web of Conferences, 227, 02005 (2021)

13. B. Sh. Matyakubov, Z. J. Mamatkulov, R. K. Oymatov, U. N. Komilov, G. E. Eshchanova, InterCarto, InterGIS, 26, 229-239 (2020)

14. N. Ch. Namozov, D. A. Kodirova, M. I. Usmonova, International journal of scientific \& technology research, 9(03), 5491-5493 (2020)

15. S. Isaev, S. Khasanov, Y. Ashirov, T. Karabaeva, A. Gofirov, In E3S Web of Conferences, 244, 02012 (2021)

16. S. K. Isaev, R. U. Rakhmonov, S. S. Tadjiev, G. I. Gozeiv, S. Z. Khasanov, In IOP Conference Series: Earth and Environmental Science, 614(1), 012147 (2020) 